\title{
Eye-specific Segregation Requires Neural Activity in Three-Eyed Rana pipiens ${ }^{1}$
}

\author{
THOMAS A. REH ${ }^{2}$ AND MARTHA CONSTANTINE-PATON \\ Department of Biology, Princeton University, Princeton, New Jersey 08544
}

\begin{abstract}
The addition of a third eye primordium to the forebrain region of a Rana pipiens embryo invariably results in the development of a series of periodic, mutually exclusive eyespecific bands in tectal lobes dually innervated by the host and supernumerary fibers. A number of investigators have proposed that such source-specific segregation arises as a compromise between two mechanisms that are normally involved in retinotectal map formation: one which is dependent on cell surface affinities to align the map and produce a rough retinotopy and a second that "fine tunes" the map by stabilizing adjacent terminals from neighboring retinal ganglion cell bodies at the expense of terminals from nonneighboring cells. In this study we have tested the idea that this second "fine-tuning" mechanism is dependent on neural activity by blocking impulse activity in the optic nerves of three-eyed tadpoles.

To assess the requirement for activity on the formation of bands, both normal optic nerves of 17 three-eyed tadpoles were crushed intraorbitally. Two weeks after this operation, the supernumerary retinal projection had debanded and spread to cover the entire tectum in a continuous fashion. By 4 weeks, however, the host optic fibers regenerated back to the tecta and began to form segregated stripes with the fibers from the third eye. Six to 7 weeks after the optic nerve crush the periodic pattern of eye-specific segregation characteristic of dually innervated tecta was again pronounced. When activity in all three optic nerves was eliminated with tetrodotoxin (TTX; embedded in a slow release plastic) during the last 3 weeks of this process, the fibers from the two competing eyes failed to segregate and, instead, formed two completely overlapping, continuous projections across the tectal surface.
\end{abstract}

To test for the requirement of activity in the maintenance of segregation, we also subjected three-eyed tadpoles without optic nerve crush to TTX blockade for 2,3 , and 4 weeks. Animals sacrificed at 2 weeks show overlap of the projections in the rostral tectum but distinct interdigitating stripes in

Received April 23, 1984; Revised August 3, 1984

Accepted September 14, 1984

${ }^{1}$ We gratefully acknowledge Drs. D. Sanes for useful discussions and L. L. Symonds for comments on the manuscript. We also thank J. Piotrowski and $\mathrm{P}$. Forrari Eastman for technical assistance and J. Nielsen for typing the manuscript. The work was supported by National Institutes of Health Grant EY05379.01 to T. A. R., National Science Foundation Grant BNS-8110225, and National Institutes of Health Grant EY01872-06 to M. C.P.

${ }^{2}$ To whom correspondence should be directed, at his present address: Department of Medical Physiology, Room 2019. Health Sciences Center, University of Calgary, Calgary, Alberta, Canada T2N1N4. other regions of these lobes. After 3 weeks of blockade, segregation of the projections was less distinct in the central tectum as well. After 4 weeks of TTX blockade the terminals from both eyes spread to form continuous overlapping projections throughout the tectum. Examination of well isolated, individual retinal ganglion cell terminal arbors during this period reveals that they occupy a significantly greater area of tectum following the TTX treatment.

These results indicate that $\mathrm{Na}^{+}$-dependent action potentials in the optic nerves of three-eyed tadpoles are necessary for the formation and maintenance of eye-specific segregation in dually innervated tecta. They are also consistent with the hypothesis that the competitive fiber interactions that "fine tune" the normal pattern of retinotectal connections are mediated by the pattern of impulses in the optic nerve.

The segregation of afferent fiber projections from two or more sources into patches, columns, or bands occurs widely in the vertebrate central nervous system. The mechanisms which mediate this segregation are not yet understood; however, several investigators have proposed that segregation might be linked to the normal process of topographic map formation (LeVay et al., 1975; von der Malsburg and Willshaw, 1976; Constantine-Paton and Law, 1978; von der Malsburg, 1979; Willshaw and von der Malsburg, 1979; Constantine-Paton, 1982). In this view, when two similarly aligned, topographically organized projections attempt to innervate the same population of postsynaptic cells, one mechanism spreads the fibers throughout the entire postsynaptic structure, while a second mechanism tends to group together those fibers from the same source. The division of the neuropil into interdigitating zones of sourcespecific termination optimizes both of these processes.

This hypothesis has received some experimental support from the retinotectal system of cold-blooded vertebrates. In normal frogs, the projection of retinal ganglion cell (RGC) axons to their terminal sites in the superficial neuropil of the optic tectum is organized as a continuous map of the retinal surface. However, when two eyes are forced to innervate a single tectum, either by the embryonic transplant of an additional eye primordium, or by the surgical removal of one tectum in a normal frog or tadpole, the terminals from the two eyes divide the tectal neuropil into a series of alternating, mutually exclusive, eye-specific bands (Constantine-Paton and Law, 1978; Law and Constantine-Paton, 1980; Straznicky et al., 1980). Surgical deflection of optic fibers to the ipsilateral tectum in goldfish have yielded a similar pattern of eye-specific segregation (Levine and Jacobson, 1975; Meyer, 1979; Springer and Cohen, 1981).

Thus, although such segregation is not present in the normal retinotectal projection, it can be experimentally induced when two eyes are forced to compete for the same postsynaptic cells. Therefore, it is likely that the mechanisms that are responsible for segregation are the same as those that operate to ensure an appropriately organized retinotopic map in normal animals. We have proposed 
(Law and Constantine-Paton, 1980) that the mechanism that spreads the fibers across the tectum is mediated by regionally varying adhesive interactions that align and grossly match appropriate regions of the retina and the optic tectum (Sperry, 1963), whereas the second mechanism, which groups fibers from the same source, is mediated by competitive interactions that stabilize adjacent terminals from neighboring RGC bodies at the expense of terminals trom nonneighboring cells. In this model, the second mechanism would normally act to "fine-tune" the retinotectal projection to its characteristic high degree of retinotopy, whereas in the three-eyed animal it would cause the axons from the same retina to terminate together.

Several possible origins of this eye-specific information have been examined in prior publications. Intrinsic differences in laterality have been shown to be uninvolved, since segregation will occur between two eyes of the same original laterality in three-eyed frogs (Constantine-Paton and Law, 1978; Straznicky et al., 1980). Histocompatibility differences between donor and host have been ruled out by the fact that the two eyes of a normal frog (Law and Constantine-Paton, 1980 ) or goldfish (Levine and Jacobson, 1975) can be made to segregate when forced to innervate a single tectum. Selective fasciculation of fibers in the optic tract is also unlikely to provide source-specific informalion since the terminals that comprise one band have been shown to travel to the tectum in numerous different age-related bundles (Constantine-Paton et al., 1983). Furthermore, experiments using compound eyes, formed by fusing embryonic retinal fragments (Fawcett and Willshaw, 1982; Law, 1983; Straz. nicky and Tay, 1982) or by inducing mirror-symmetric duplication of eye primordia by partial ablation (Fraser et al., 1982), have demonstrated that ganglion cell arbors from the two half-eyes will segregate in the tectum. This indicates that axon terminals from cells of a single continuous presynaptic sheet will segregate in the tectal neuropil, depending only on differences in the position of the ganglion cell somas.

In this report we have tested the hypothesis that $\mathrm{Na}^{+}$-dependent action potentials in the optic nerves provide the information that RGC terminals arise from neighboring retinal cells and thereby cause torminals from different cyos of a threc cycd frog to scgregatc into eye-specific stripes

\section{Materials and Methods}

Animals. The animals used in this study were laboratory-reared Northern leopard frogs, Rana pipiens. Adult breeders (J. M. Hazen \& Co., Alburg, VT) were ovulated and the eggs were fertilized artificially. Three-eyed animals were produced by transplanting an eye primordium from a Shumway stage 17 to 19 embryo (Shumway, 1940) into the forebrain region of a sibling at the same stage. Further details of the operation and the animal rearing procedures have been published previously (Law and Constantine-Paton, 1981). Animals were kept in a constant $23^{\circ} \mathrm{C}$ environment with a 12-hr light/ dark cycle throughout their rearing and the experiments described in this study

Elvax-4OP. In order to ensure a sustained release of tetrodotoxin (TTX) over a relatively long period, we suspended the material in a slow release plastic, ELVAX-4OP (a gift from DuPont Co., Wilmington, DE), using the method described by Silberstein and Daniel (1982). The rate of release of fluorescein, a substance close in molecular weight to TTX, was determined using absorbance measures at $460 \mathrm{~nm}$ from a Beckman spectrophotometer.

With daily changes of solution, we found that an initial rapid release of fluorescein was followed by a slow decline of from $10^{-8} \mathrm{~mol} / \mathrm{hr}$ to $10^{-11} \mathrm{~mol} /$ hr over the next 40 days. This rate of release is consistent with the protracted time course of release found when other materials have been embedded in Elvax (Langer and Folkman, 1976; Rhine et al., 1980; Silberstein and Daniel, 1982). Since $T T X$ is effective at concentrations as low as $10^{-7} \mathrm{M}$ (Harris 1981) and we estimated the intraocular fluid to be between 50 and $100 \mu l$ we reasoned that a release rate of $10^{-11} \mathrm{~mol} / \mathrm{hr}$ would still be sufficient to effectively block RGC action potentials. Therefore, TTX (Sigma Chemical Co., St. Louis, MO) was suspended in the Elvax in the same manner as for fluorescein ( $1 \mathrm{mg} / \mathrm{gm}$ of Elvax), and its rate of efflux was presumed to be similar. The Elvax pellets containing the TTX (TTX-Elvax) were used in two ways in our experiments. In one series of animals small pellets, approximately $1 \mathrm{mg}$, were placed in the posterior eye chamber through an incision made in the cornea. The eyes were then sealed with Histoacryl tissue glue and they subsequently healed with the Elvax pellet inside. In another group of tadpoles, the optic nerves were exposed and threads of Elvax, which had been stretched from small pellets, were tied around the nerves. Again the incision was sealed with tissue glue and the Elvax cuffs usually stayed in place for several weeks postoperatively. Immediately after the implant of TTX-Elvax, the tadpoles were usually completely paralyzed, and it was found necessary to oxygenate their water continuously for the first 2 or 3 days. After this the water was oxygenated approximately $12 \mathrm{hr} /$ day in both control and experimental animals

Optokinetic response. To assess the effectiveness of the $\Pi \mathrm{X}$-containing Elvax in blocking the retinotectal impulse transmission, both behavioral and electrophysiological techniques were employed.

For the behavioral test we examined the optokinetic response (OKR) in the tadpoles prior to and following the insertion of the Elvax. The OKR can be elicited very reliably in normal tadpoles by placing them in a small dish under a slowly rotating plastic dome that has been marked with an alternating pattern of light and dark vertical stripes. When this dome is rotated in either the clockwise or counterclockwise direction, a highly stereotyped response is evoked. As the rotation of the dome begins, the animal's tail flexes in a direction opposite site to that in which the stimulus pattern is turning. Soon after, the tadpole begins to swim in a circular manner, with the direction and speed of the rotating dome. The OKR was tested in TTX-treated tadpoles on alternate days during their 1 - to 4 -week survival.

Flectrophysiological recording. Tadpoles to be used for physiological recording were anesthetized with methanesulfonic acid (MS-222) and both optic tecta were exposed; the animals were then paralyzed with succinylcholine and all wound surfaces were treated with lidocaine. In addition, a small cannula was cemented into the mouth and oxygenated charcoal-filtered water was continuously perfused through the gills via a peristaltic pump. Electrical activity was recorded using tungsten in glass microelectrodes, amplified via a Grass extracellular amplifier and further procesed with a Computerscope digital oscilloscope (R. C. Electronics, Inc., Santa Barbara, CA). Stimuli for the field potential analysis were delivered with a Grass strobe stimulator.

Since the animals frequently did not survive the recording sessions, the three-eyed tadpoles were not examined in this way. Instead, a group (10) of normal tadpoles at midlarval stages (Taylor and Kollros, 1946; T\&K stages XII to XVIII) received unilateral intraocular pellets or nerve cuffs of TTXcontaining Elvax and were examined for the effectiveness of the implants at weekly intervals. Figure 1 shows the averaged response of 40 flashes to the

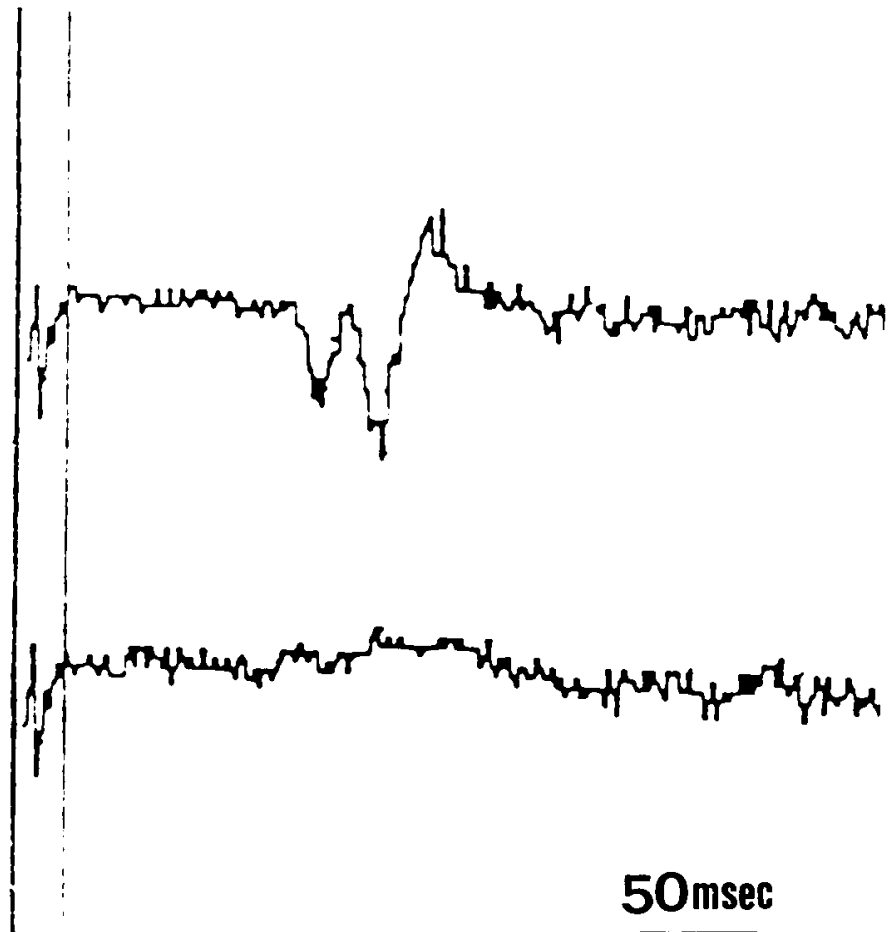

Figure 1. Averaged responses to 40 strobe flashes recorded in the tectal neuropil of a tadpole that has had a TTX-containing Elvax cuff on one optic nerve for 3 weeks. The upper trace shows the response recorded from the tectum ipsilateral to the TTX blocked norve; the lower trace shows the response recorded from the contralateral tectum. 
normal and poisoned eyes as recorded in the superficial tectal neuropil 3 weeks after a TTX-Elvax cuff was placed on the animal's left optic nerve. Even after 3 weeks the TTX is being released at a high enough concentration to poison the optic nerve. Moreover, no single- or multiple-unit activity could be evoked from the TTX-poisoned retinas of any of these animals using a variety of visual stimuli. From these recording sessions we determined that the Elvax was releasing TTX at effective concentrations to block all activity in the optic nerves for at least 3 weeks. However, removal of the cuffs in two animals after 1 week resulted in the recovery of visual responsiveness within $24 \mathrm{hr}$.

Histochemistry and autoradiography. To label both of the projections to the dually innervated tecta of three-eyed tadpoles we used the doublelabeling technique described in an earlier publication (Constantine-Paton el al., 1983). Briefly, $\left[{ }^{3} \mathrm{H}\right]$ proline $(10$ to $15 \mu \mathrm{Ci})$ was injected into the two normal eyes while a small recrystallized pellet of horseradish peroxidase (HRP; Sigma) was placed on the cut end of the third nerve. The tadpoles were allowed to survive for 1 to 2 days for adequate transport of the labels, and the brains were reacted as whole mounts following a modification of the procedures of Fugisawa et al. (1981) as described in Reh et al. (1983). The brains were then photographed, fixed in Bouin's solution, dehydrated, and embedded in paraffin. Sections were cut at $10 \mu \mathrm{m}$ and processed with standard autoradiographic techniques so that both labels could be visualized in the same section.

In those cases in which the ganglion cell terminals were to be traced, the third nerve was labeled with a small pellet of HRP that had been dried onto the tip of a pin. These brains were also reacted as whole mounts. They were then split at the rostral and caudal poles and dried flat onto a slide. After they had been cleared in xylene and coverslipped, well isolated terminals were drawn at $\times 1000$ using a Leitz drawing tube.

Morphometry. The average RGC areas and numbers were determined for similarly staged normal and chronically poisoned tadpoles from $10-\mu \mathrm{m}$ paraffin sections through the dorsoventral axis of their retinas following fixation in Bouin's solution. For the cell numbers, all large, clear nuclei in the ganglion cell layer were counted in every 10th section through the retinas. This sampling method has been shown to provide an accurate estimate of total RGC numbers and is described in more detail in a previous publication (Reh and Constantine-Paton, 1983). Cross-sectional areas of cells in the ganglion cell layer were measured from toluidine blue-stained sections by projecting the retinas directly with a Leitz Dialux 20 microscope and drawing tube onto a Summagraphics bit pad interfaced with a Terak 8510 microcomputer. Approximately 200 cells/retina were measured. The areas of RGC terminals from their first branch points were measured using this same system, by first drawing the entire terminal arborization and then measuring the envelope of the arbor with the bit pad (Constantine-Paton et al., 1983).

\section{Results}

Retinotectal projection in normal and three-eyed tadpoles. When HRP pellets are placed on the cut optic nerves of normal tadpoles, the entire projection is labeled. The normal retinotectal projection is completely crossed and forms a continuous dense network of axonal arborizations throughout the superficial tectal neuropil (layers 7 to 9). However, in all tadpoles the projection fails to cover a small region of the caudomedial tectum where cell division and differentiation are still occurring (Currie and Cowan, 1974; Reh and Constantine-Paton, 1983).

In the three-eyed tadpoles there is a striking difference when the projection from the third eye is labeled with HRP and the brain is reacted as a whole mount (Constantine-Paton and Law, 1978: Constantine-Paton, 1982). The projections of both the host and the supernumerary optic nerves in a dually innervated tectum are divided into a series of regular alternating bands (e.g., Figs. $2 e, 3, b$ and $d$, and $4 a$ ). The fact that the third eye bands interdigitate with the host eye projection has been shown in previous publications (Law and Constantine-Paton, 1981; Law, 1982), in which the host retinal projection has been labeled with $\left[{ }^{3} \mathrm{H}\right]$ proline and the third eye has been labeled with HRP. Several features of these dual projections are noteworthy in their similarity to the normal tadpole: (1) as Figure $6 a$, shows, the retinotectal terminals in dually innervated tecta still terminate through the full depth of the superficial neuropil; (2) the projections of each eye cover approximately the same area of tectum, but as in the normal tadpole thcy never completely reach the most caudomedial region of the structure (see Fig. 4a); and (3) previous physiological investigations have demonstrated that both retinal projections are aligned according to the initial embryonic axes of the eye primordia (Law and Constantine-Paton, 1981).

The third eye projection spreads following crush of the normal nerves. The initial segregation of optic fibers into eye-specific bands occurs very early during development; segregation is present at T\&K stage IV, which is as early as we have been able to use the neuroanatomical tracing methods. Therefore, in order to study the effects of silencing optic nerve activity on the formation of eyespecific bands, the projection of the third nerve was allowed to spread over the tectum by crushing the normal optic nerves, and the process of resegregation was studied as the host nerve fibers regenerated to the tectum.

A total of 30 three-eyed tadpoles at midlarval stages received bilateral optic nerve crushes, leaving the third nerve intact. Fourteen of these animals were used to examine the normal time course of debanding and rebanding using the double-labeling technique; in all cases the normal eyes were labeled with $\left[{ }^{3} \mathrm{H}\right]$ proline and the supernumerary nerve was labeled with HRP. Following crush of the optic nerves in these tadpoles, most of the severed axons and their tectal terminals degenerated within 1 week.

The time course of degeneration was determined by severing the optic nerve and using the anterograde transport of HRP to visualize the terminals over the next several days. After 2 days al $23^{\circ} \mathrm{C}$, the terminals were well labeled and appeared structurally intact; however, by 3 days they showed definite signs of degeneration (e.g., beaded). By 4 days after the optic nerve was severed, the axons and terminals were hardly recognizable as such, and instead the label had a yranular appearance indicating that the beaded axons and endings had fractionated. In the next few days this granular label becomes much less intense as the degenerated terminals are cleared from the tectum. This time course of degeneration is consistent with that observed in unlabeled optic fibers in larval Xenopus (Gaze et al., 1979; Ostberg and Norden, 1979) and therefore is unlikely to be due to necrotic effects of the HRP itself.

With the degeneration of the host RGC terminals, the terminals of the third nerve soon began to spread into the interband region. Figure 2, $a$ and $b$, shows the whole mounted brain of an animal after the supernumerary optic nerve was labeled with HRP. This tadpole received a bilateral crush of the host optic nerves 11 days earlier. Although one can still discern the regular striped pattern, the supernumerary projection has spread to the interband regions and the edges of the bands have become less distinct. By 15 days after the operation there is little evidence of the original banding; the fibers from the third eye cover the tectum in a fairly continuous fashion (Fig. 2c).

As the host optic nerves began to regenerate, the fibers entered the tectum and grew selectively into the superficial neuropil. Three weeks atter the crush, autoradiography revealed that the regenerating axons had reached the tectum. At this time, however, there was still no evidence of segregation of the two projections; the HRP-filled terminals of the third nerve still projected continuously across the tectum. Four weeks after the bilateral host optic nerve crush, eyespecific bands began to form. This segregation can be seen both in the projection of the third nerve (Fig. 2d), labeied with HRP, and in the terminals of the regenerated host nerve, labeled with $\left[{ }^{3} \mathrm{H}\right]$ proline. This segregation of the projections became more pronounced with time, and by 6 weeks after the optic nerve crush, the periodic banding pattern was indistinguishable from that of unoperated three-eyed tadpoles (see Fig. 4a). Figure $2 e$ shows the whole mounted brain of a tadpole that sustained a bilateral crush of the host optic nerves 10 weeks earlier. It should be noted that the regular striped pattern seen in three-eyed tadpoles was often (although not always) much more patch-like following regeneration. We have earlier proposed that patches, rather than stripes, occur when the innervation density falls bolow a certain critical value (Law, 1982). This is entirely consistent with the appearance of patchy termination in 

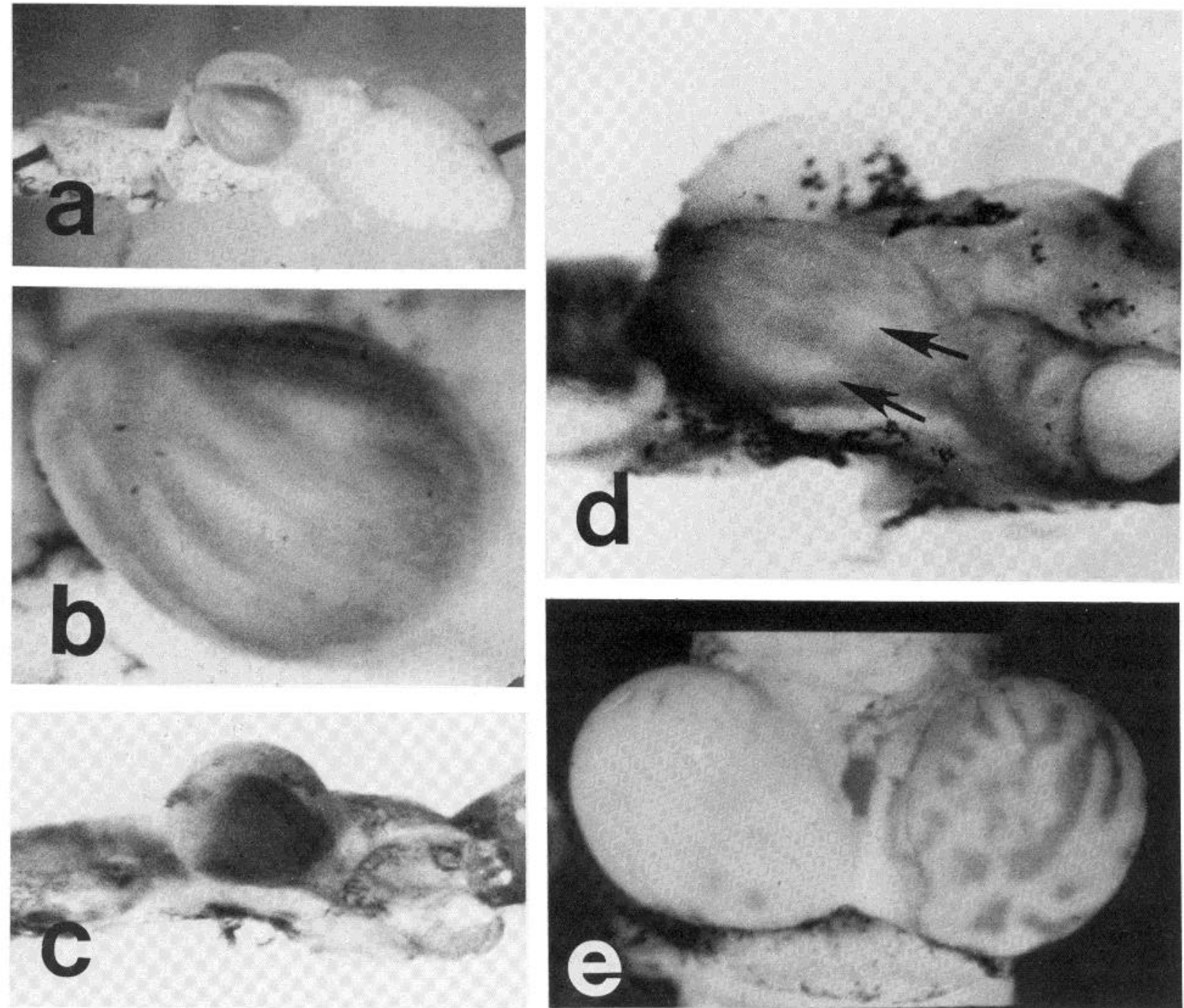

Figure 2. Whole mounted brains of three-eyed tadpoles in which the fibers from the third eye have been labeled with HRP at progressively later times after the bilateral crush of the host optic nerves. The brain shown in $a(\times 8)$ and $b(\times 33)$ was labeled and processed 10 days after crush of the host optic nerve. Note that, although the bands are still present, they are much less distinct as fibers spread into the interband region. This process is largely complete by 2 weeks $(c, \times 13)$. By 3 weeks, however, the fibers from the host eyes have begun to regenerate, and slight bands once again begin to form (arrows in $d, \times 20)$, and by 7 weeks after the nerve crush $(e, \times 20)$, the host optic nerve fibers have regenerated and completely resegregated to again form the banded pattern characteristic of three-eyed animals.

regenerates, since it is likely that fewer than normal fibers reach the tectum.

$\Pi \Pi X$ blocks resegregation following regeneration of the host optic nerves. Twelve three-eyed tadpoles (T\&K XII-XVI) received bilateral host optic nerve crush and, 4 weeks later, after the normal optic fibers had regenerated to the tectum, had all three optic nerves poisoned with TTX-Elvax, applied either as intraocular pellets or as optic nerve cuffs. Four additional control animals received bilateral host optic nerve crushes; however, Elvax without TTX was used for the intraocular pellets and optic nerve cuffs. Of the five experimental animals that survived the 3-week TTX treatment, three were successfully processed for both $\left[{ }^{3} \mathrm{H}\right]$ proline autoradiography and HRP histochemistry, whereas one animal only had label in the supernumerary optic fibers. In two of the four control animals both the normal and third eyes were labeled, whereas in the other two, only the third nerve was labeled with HRP. The result of blocking activity in the optic nerves for 3 weeks, between the fourth and seventh weeks after the initial bilateral optic nerve crush, was consistent for all animals: segregation into eye-specific bands was prevented only in those cases in which the Elvax contained TTX.

Two examples of whole mounted brains from tadpoles treated with TTX are shown in Figure 3, $a$ and $c$. The brains of two control animals are shown in Figure $3, b$ and $d$, for comparison. Although the Elvax alone does not disrupt band formation, segregation is prevented when the TTX is used to block the activity in the optic nerve. Since the host eyes were labeled with $\left[{ }^{3} \mathrm{H}\right]$ proline, it was possible to determine that the regeneration of the host optic nerves had not been slowed or prevented by the TTX. Although the autoradiographic process does not allow a quantitative measure of the number of regenerating fibers or their rate of growth, in all cases the autoradiographs showed that the host optic nerves had regenerated and overlapped in a continuous dense projection with the supernumerary eye.

TTX prevents maintenance of segregation. In another group of three-eyed tadpoles the optic nerves were poisoned without prior crush to study the effects of TTX on the maintenance of the banding pattern. Intraocular pellets or nerve cuffs of TTX-Elvax were implanted in a total of 29 midlarval stage three-eyed tadpoles. Evidence that the TTX was effective in silencing activity in the optic nerves of these animals was provided by testing the tadpoles for the presence of an optokinetic turning response, as described previously. When responses in either direction returned, or when a particular animal 
Figure 3. Whole mounted brains of four three-eyed tadpoles in which the host optic nerves were crushed 7 weeks before labeling the third nerve with HRP. The brains shown in $a$ and $c$ are from animals that had all three eyes poisoned with $\Pi \mathrm{TX}$ during the first 3 weeks, and those shown in $b$ and $d$ are from tadpoles in which Elvax pellets without TTX were added in all three eyes during the same period. All brains are at approximately the same magnification $(\times 22)$. Rostral is to the right for $a, c$, and $d$, and to the left for $b$.
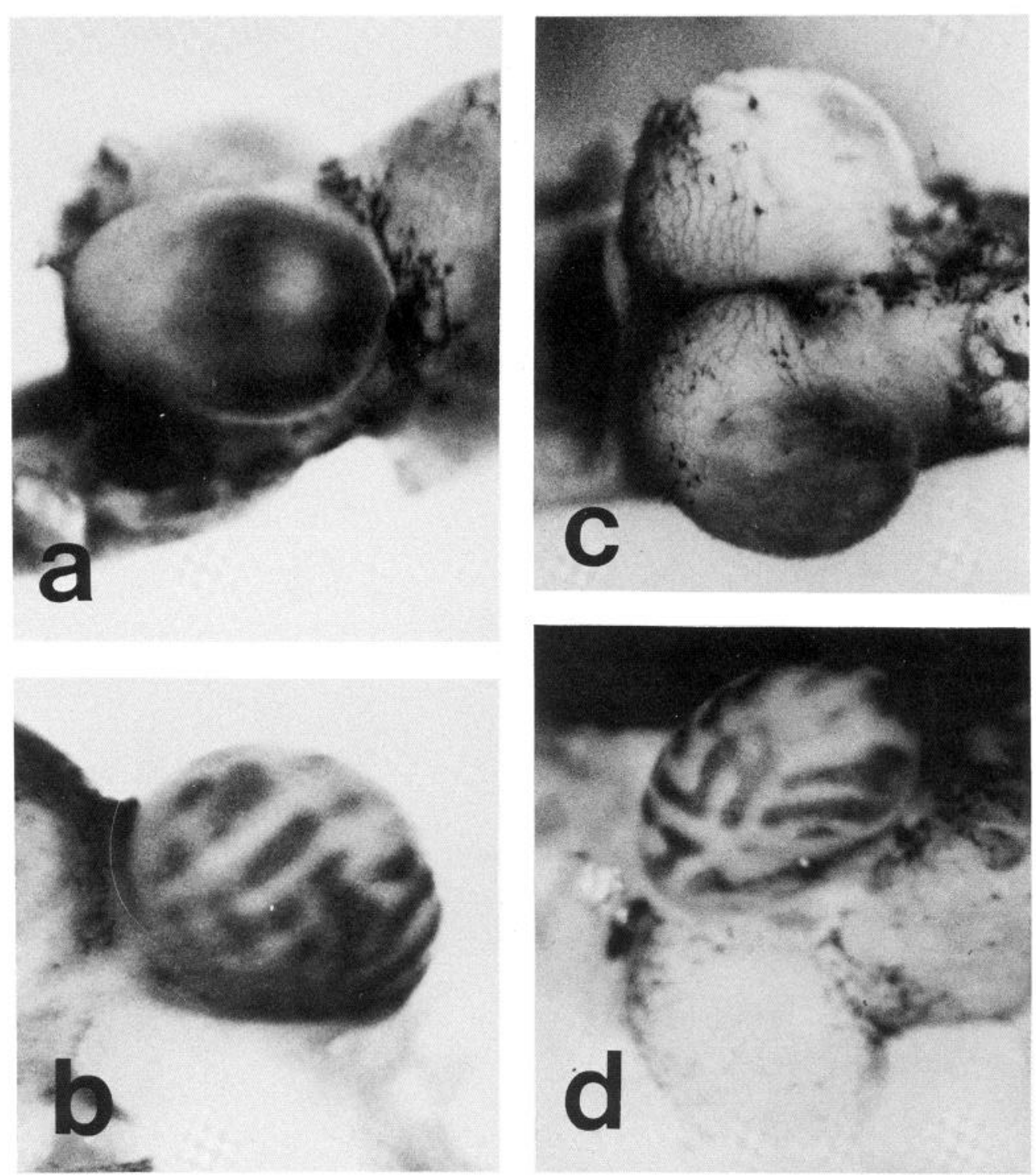

began to look sickly, the optic nerves were labeled with HRP or $\left[{ }^{3} \mathrm{H}\right]$ proline and the brains were reacted for these labels. Twelve animals survived the implants for varying lengths of time and were successfully processed for the labels; 3 tadpoles were poisoned for 2 weeks, 4 tadpoles were poisoned for 3 weeks, and 5 tadpoles were poisoned for 4 weeks.

Over the 4-week period in which the activity in the optic nerves was eliminated, there was a progressive spreading of fibers from their eye-specific bands, into the interband regions. Figure $4 b$ shows a whole mounted brain of a three-eyed tadpole in which the optic nerves had been continuously silenced by the TTX over a 2-week period. After 2 weeks of poisoning, the eye-specific bands are still clearly present in the central tectum; however, in the rostral tectum, the segregation is less distinct. When the brains of these animals were sectioned and processed for autoradiography, there was considerable overlap between the HRP-containing terminals and the $\left[{ }^{3} \mathrm{H}\right]$ proline-containing terminals in the sections of rostral tectum, but segregation between the two labels was still evident in more central tectal sections.

After 3 weeks of silencing the optic nerves in three-eyed tadpoles, the changes in the normal segregated pattern became even more pronounced. It is still possible to distinguish band and interband regions of the dually innervated tectum, but the boundaries are much less distinct, and one can now see overlap between the host and third eye terminals throughout the tectum in the sectioned material. As in the 2-week cases, the overlap is still most pronounced in the peripheral tectum with some segregation still present in the central tectum.

Four weeks after the three-eyed animals received TTX-Elvax implants, there was little evidence of eye-specific segregation of terminals. Figure 4, $c$ and $d$, shows the whole mounted brains of two three-eyed tadpoles that had TTX-Elvax cuffs placed on all nerves for 4 weeks; the third nerve was labeled with HRP and the terminals of the host eye were labeled with intraocular injections of $\left[{ }^{3} \mathrm{H}\right]$ proline in each case. By this time, the terminals from the third eye no longer show eye-specific bands but spread evenly across the entire tectal surface. Likewise, the projection of the host eye also shows no banded pattern in the autoradiographs (see Fig. $6, b$ to $e$ ), as contrasted with the striking striped pattern seen in the autoradiographs of untreated or control three-eyed tadpoles (see Fig. 6a). In three control animals, Elvax pellets without TTX were implanted intraocularly, and after 4 weeks, examination of the projections of the three eyes (Fig. $4 a$ ) showed the normal pattern of segregation present in three-eyed tadpoles.

In some cases, following reaction with diaminobenzidine, the optic tecta of the tadpoles were mounted flat on slides, fixed, and cleared. Figure 5 shows micrographs of such tecta from three-eyed animals detailing the sequence of debanding with TTX treatment. In the 

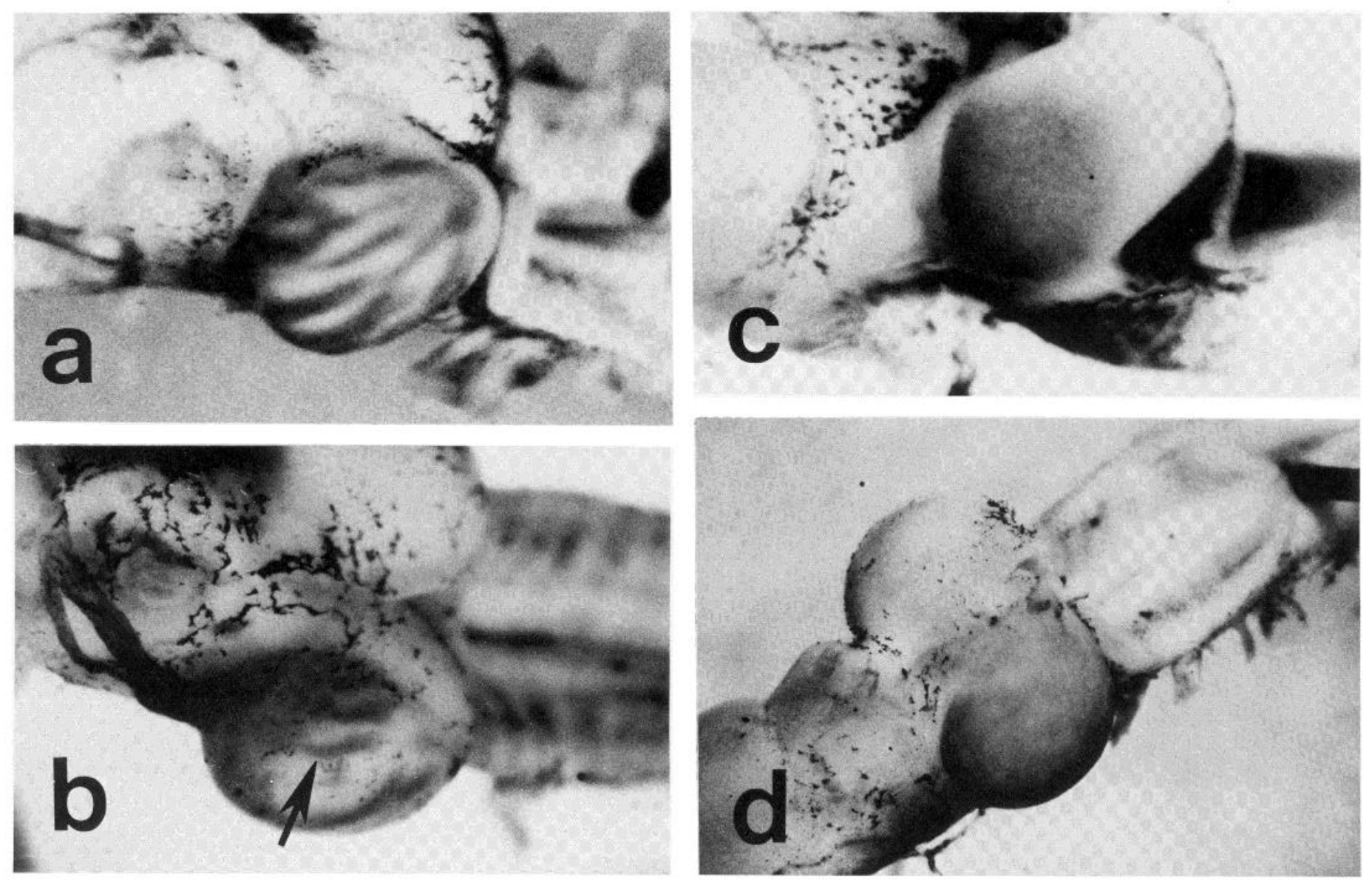

Figure 4. Whole mounted brains of four three-eyed tadpoles in which the third nerve was labeled with HRP. The brain shown in a is from an animal that had intraocular pellets of Elvax without TTX in all three eyes for 4 weeks. The brain shown in $b$ had all nerves poisoned with TTX-containing Elvax cuffs for 2 weeks; notice that the rostral half of the tectum is continuously labeled, whereas stripes are still present in the caudal half (arrow). In $c$ and $d$ the brains are from tadpoles in which all activity was blocked by a TTX-containing Elvax as intraocular pellets $(c)$ or as cuffs around all nerves $(d)$ for 4 weeks. No evidence of stripes can be seen at this time. All brains are at approximately the same magnification $(\times 20)$, with $d$ at a slightly lower power. Rostral is to the left in all of the photographs.

case shown in Figure 5, a to $d$, the three-eyed animals had all three eyes silenced with TTX for progressively longer periods of time, with a correspondingly greater degree of debanding. After 3 weeks of TTX treatment (Fig. $5 d$ ), there is again little evidence of stripes. The higher power views in Figure $5, e$ and $f$, show an untreated animal (Fig. $5 e$ ) and a tadpole that had all three optic nerves blocked with TTX for 3 weeks (Fig. 5f). Although control three-eyed animals have a few fibers running between the stripes, the region of dense arborization is within the stripes (Fig. 5e). However, in the TTXtreated animals, the terminal arborizations have now spread into the former interband regions (Fig. $5 f$ ).

Changes in terminal arbors with $T \mathrm{TX}$. The tecta of 11 normal tadpoles and 6 three-eyed tadpoles were flat mounted and cleared following small localized injections of HRP into the optic nerve or tract. In these tecta, axon terminal arbors could frequently be visualized in a sufficiently low density to enable us to trace them in their entirety with the camera lucida. The terminal arbors of normal tadpoles have been described previously (Reh and ConstantinePaton, 1984); therefore, only those terminals drawn from the threeeyed tadpoles will be detailed.

As in the normal tadpole, the axon terminals in three-eyed tadpoles were of two major classes. The most superficial terminal arbors had parent axons of very fine caliber that gave rise to branches of approximately the same diameter as the parent fiber. Few examples of this type were drawn, as they usually showed signs of significant degeneration with the survival times we used. The second type of terminal arbor had a parent axon of intermediate caliber and was located at an intermediate depth within the neuropil. Most of the terminal arbors that were drawn, and all of those in which the area was measured in this study, were of this type. The morphology of these arbors was found to vary slightly with the position of the terminal along the rostrocaudal axis of the tectum; however, the major features remained constant. The parent fiber typically split into two or three major branches that then give rise to numerous finer branches in a restricted locus on the tectum (Fig. 7a). The overall area over which this more profuse arborization occurred was measured for 10 terminals from three-eyed tadpoles and 9 terminals drawn from similarly staged normal tadpoles. No significant difference (Mann-Whitney $U$ test) was found in the overall tangential area of the terminal arbors from the two classes of animals; therefore, they were grouped together (Fig. 8). In both the three-eyed tadpoles and the normal animals, the terminal arbors were more extensive along the rostrocaudal axis than along the mediolateral axis, and the terminal arbors in the rostral tectum occupied a somewhat smaller area than did those in the caudal tectum (Constantine-Paton et al., 1983; Reh and Constantine-Paton, 1984). An additional feature of the terminals of the three-eyed animals is that the region of profuse arborization was always within a band of other labeled fibers even though the main axon cylinder of these terminals often crossed interband regions in their course from the tract.

It was also possible to draw and measure 17 of the larger class terminal arbors of three-eyed animals that had been poisoned for 2 to 4 weeks. An example of a typical terminal arbor from such an animal is shown in Figure $7 \mathrm{~b}$. Several aspects of these arborizations 

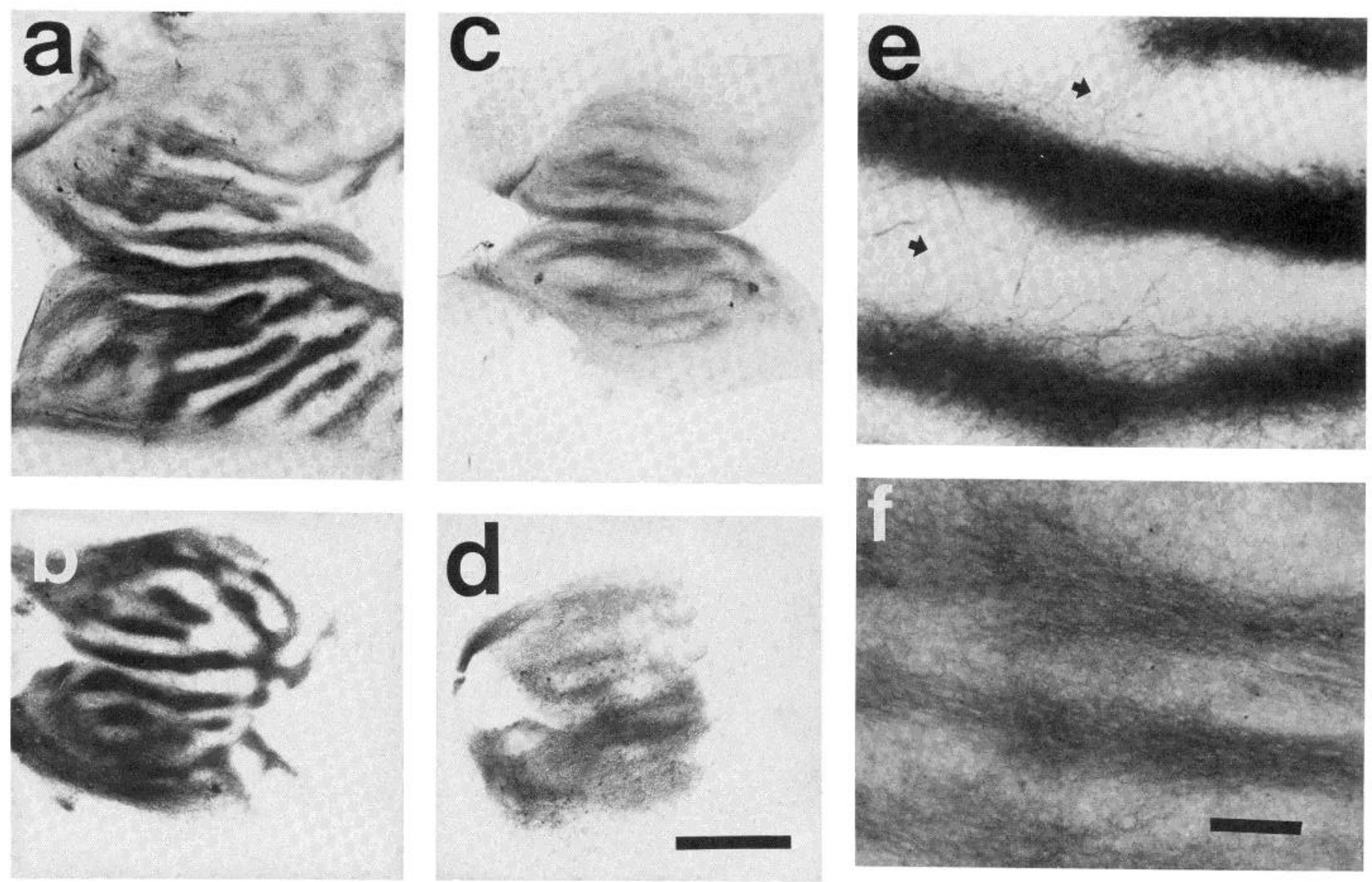

Figure 5. Flat mount preparations of optic tecta from three-eyed tadpoles following anterograde labeling with HRP of the third optic nerve. The animal whose tecta is shown in a had all three optic nerves silenced with TTX for 1 week. Note that there is a slight spreading of the fibers from the bands to the interband regions in rostral tectum (to the left); however, most of the terminals remain well segregated. In $b$ to $d$ the bands become progressively less distinct in animals treated with TTX for 2 weeks $(b)$ and 3 weeks ( $c$ and $d$ ). In $e$, higher power views of flat mounted tecta from three-eyed animals show that, in the normally segregated projection, only a few axons pass between the bands (arrows), whereas in the TTX-treated animal fine arborizations have spread into the formerly interband regions. $a$ to $d$ are at the same magnification; scale bar $=500 \mu \mathrm{m}$. $e$ and $f$ are at the same magnification; scale bar $=$ $100 \mu \mathrm{m}$.

are noteworthy in their differences from those of the untreated threeeyed tadpoles. Many of the branches of the terminal arbors from the TTX-poisoned animals extend into the interband region, whereas in the untreated three-eyed animal the fine branches of the arbor are almost entirely confined to the bands of their eye of origin. Also, the arbors from the TTX-treated animals are more variable in their overall areal extent and on the average occupy a significantly greater tectal area (Mann-Whitney $U$ test, $<0.002$ ) than do those from the untreated, dually innervated tecta. This can be seen more easily in Figure 8 , where the areas of the terminal arbors have been plotted for both TTX-treated and nontreated three-eyed animals and similarly staged normal tadpoles.

RGCell number and area following chronic TTX treatment. To determine the effects of chronic TTX treatment on the retinal cells, the total number of ganglion cells in both eyes of 13 midlarval staged ( $T \& \mathrm{~K} X$ to $\mathrm{XVI}$ ) tadpoles was calculated as described under "Materials and Methods." The ratio of right to left eye cell counts for four normal animals is plotted in Figure 9, along with the ratios of the RGC numbers from the TTX-treated eyes to those in the control eyes in animals that received a TTX-Elvax pellet in one eye or as a cuff around one nerve for 20 to 40 days. It can be seen from Figure 9 that no appreciable loss of cells occurs in the TTX-treated eye, even after 40 days. Moreover, no differences in overall numbers of RGCs were found between the TTX-treated tadpoles and those values reported previously for similarly staged tadpoles (Reh and Constantine-Paton, 1983), indicating the absence of a systemic effect of the TTX on the growth and development of the larvae.

The average area of cells in the ganglion cell layer was also determined in seven of the same tadpoles in which activity was blocked monocularly with TTX for between 20 and 40 days. The average somal area of cells in this layer was $51.41 \pm 5.88 \mu \mathrm{m}$ for the control eye and $53.67 \pm 6.61 \mu \mathrm{m}$ for the TTX-treated eye. The small increase in mean cell area following the TTX administration, although not statistically significant, may indicate a slight chromatolytic response, similar to that observed in motoneurons following muscle paralysis with TTX (Czeh et al., 1978).

\section{Discussion}

Previous studies in three-eyed frogs have eliminated several factors from consideration as potential mechanisms by which the fibers

Figure 6. Sections through the tecta of three-eyed tadpoles to show the double-label technique. The sections shown in $a$ and $b$ were illuminated in darkfield and the sections shown in $c$ to $e$ were photographed under brightfield illumination. The brain shown in $a$ is from an animal that had Elvax pellets in all three eyes without TTX, showing the regular alternating banded pattern characteristic of doubly innervated tecta. The section shown in the remaining micrographs is from a three-eyed tadpole in which all three optic nerves were poisoned with TTX for 4 weeks. In the low power micrographs ( $b$ and $c$ ), the even distribution of both labels can be seen, and in the higher power micrographs ( $d$ and $e$ ), the fibrous nature of the HRP-filled axons ( $d$ ) and the grains from the autoradiographic label $(e)$ are in focus. In both the control and the TTX-poisoned cases the host nerve was labeled with [ ${ }^{3} \mathrm{H}$ ]proline and the third nerve was labeled with HRP. Scale bars $=200 \mu \mathrm{m}(a), 400 \mu \mathrm{m}(b$ and $c)$, and $50 \mu \mathrm{m}(d$ and $e)$. The white rectangle in $c$ outlines the area shown in $d$ and $e$. 

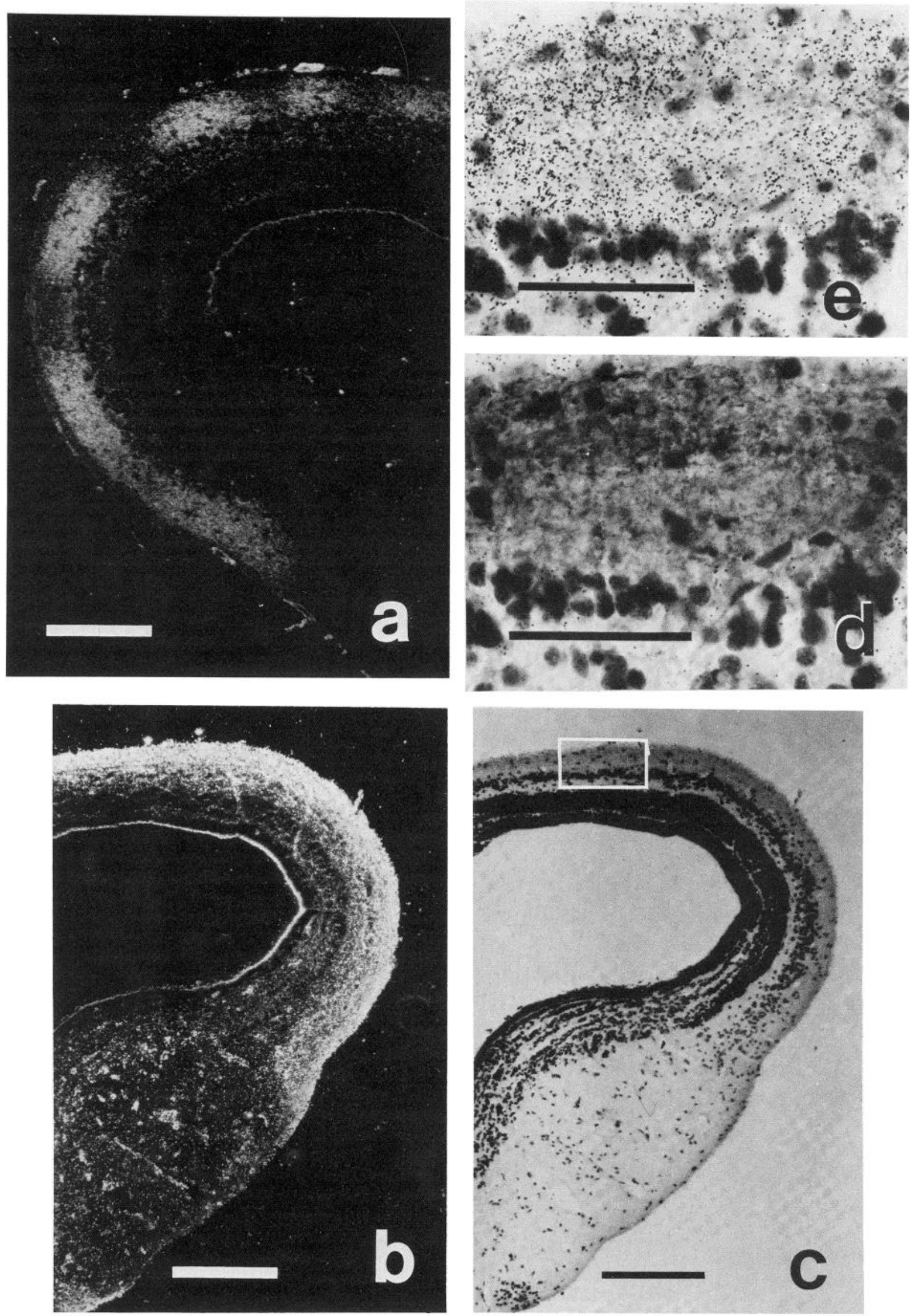

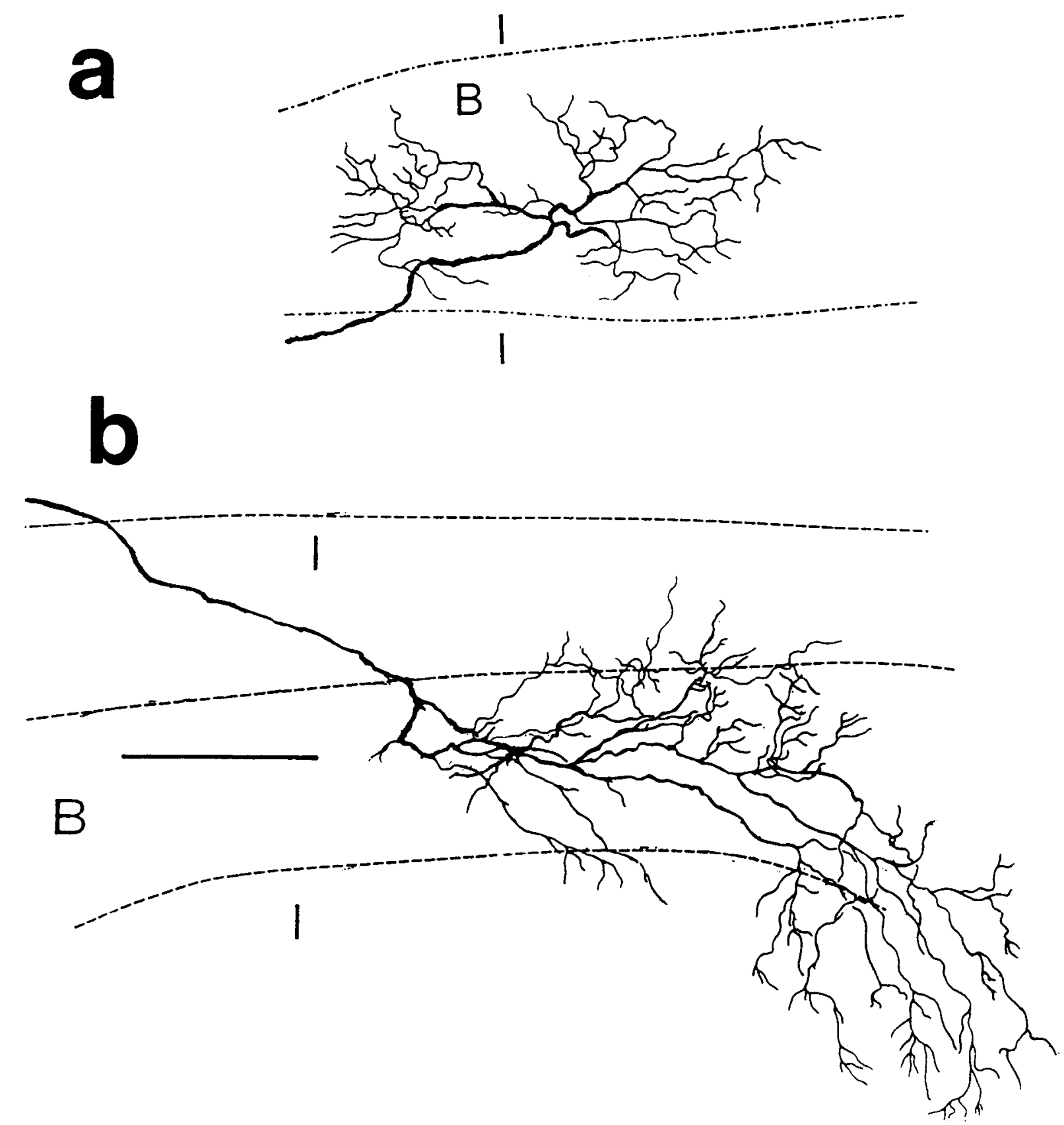

Figure 7. Camera lucida drawings of retinal ganglion cell terminal arbors from the third eye labeled with HRP and drawn from approximately the same region (central) of flat mounted tecta. The terminal arbor shown in a is from a three-eyed tadpole without TTX treatment, and that shown in $b$ is from an animal that had all three eyes poisoned for 3 weeks. Notice that the terminal in a has its long axis oriented with the band and its branches are confined to the band $(B)$ containing the rest of the terminals from that eye, whereas that in $b$ has many branches in the interband $(I)$ regions which, prior to the $T T X$ treatment, only contained terminal arbors from the host eye. In general, the arbors of three-eyed tadpoles have an average width (short axis) that is slightly smaller than that of the bands they occupy; however, following TTX treatment, both the short and long dimensions increase. Scale bar $=100 \mu \mathrm{m}$.

from the two eyes are able to segregate in dually innervated tecta. As mentioned in the introduction, intrinsic laterality differences, histocompatibility differences, or different trajectories of fibers from the two eyes have all been shown to be uninvolved in the ability of optic terminals to "recognize" their source and segregate accordingly (Constantine-Paton and Law, 1978; Law and Constantine-Paton, 1980; Constantine-Paton et al., 1983). Furthermore, eye-specific segregation is a robust phenomenon that occurs over a wide range of innervation densities (Law, 1982; Norden and Constantine-Paton, 1983) and is not disrupted by dark rearing (Law, 1982).

The results presented in this study indicate that the neural activity in the optic nerves of three-eyed tadpoles is involved in the process of eye-specific segregation. Chronic blockade of $\mathrm{Na}^{+}$-dependent action potentials prevents segregation between the fibers of the third eye and the host eye during regeneration of the host optic nerve. Moreover, the fibers in previously formed eye-specific bands desegregate when the activity in the optic nerves is blocked with TTX, indicating that the maintenance of segregation is also activity dependent

This conclusion is further supported by similar recent studies in the goldfish (Boss and Schmidt, 1982; Meyer, 1982) in which repeated intraocular injections of TTX were found to prevent eyespecific segregation when optic fibers from both eyes were surgically forced to regenerate to the same tectum. 


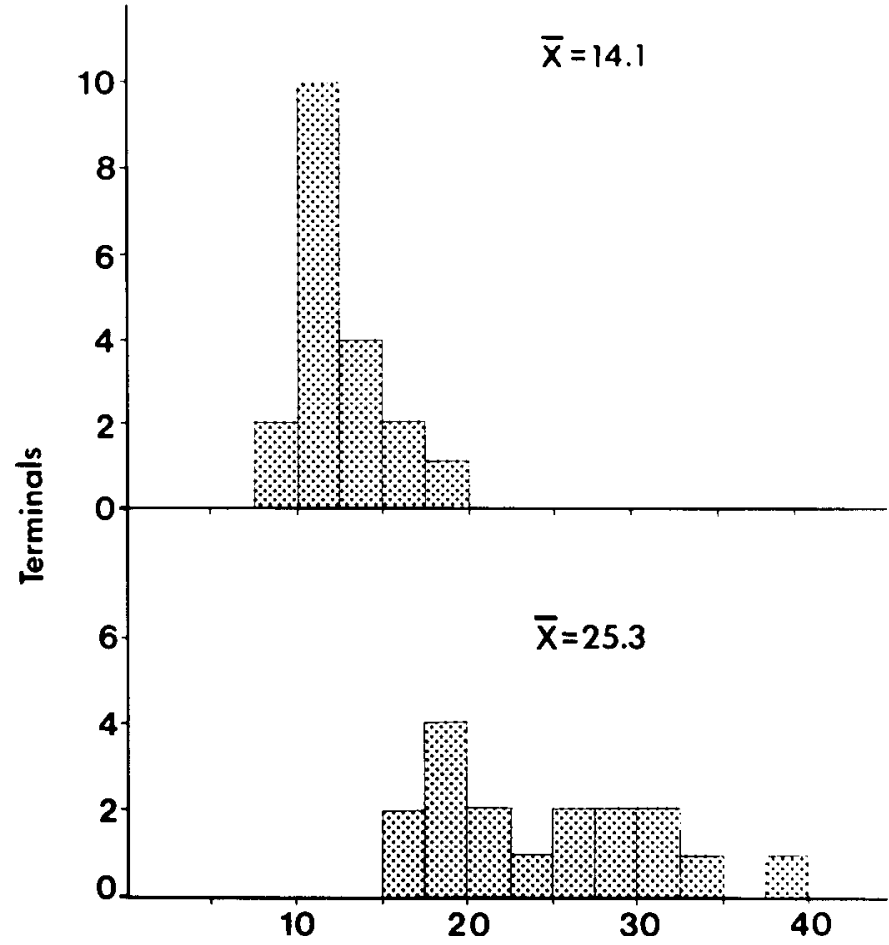

\section{Area $\left(\times 10^{3}\right) \mathrm{\mu m}^{2}$}

Figure 8 . The number of terminals is plotted according to their area for control tadpoles (normal and three-eyed not treated with TTX) in the upper histogram and for TTX-blocked three-eyed tadpoles in the lower histogram. Means for both groups are also included.

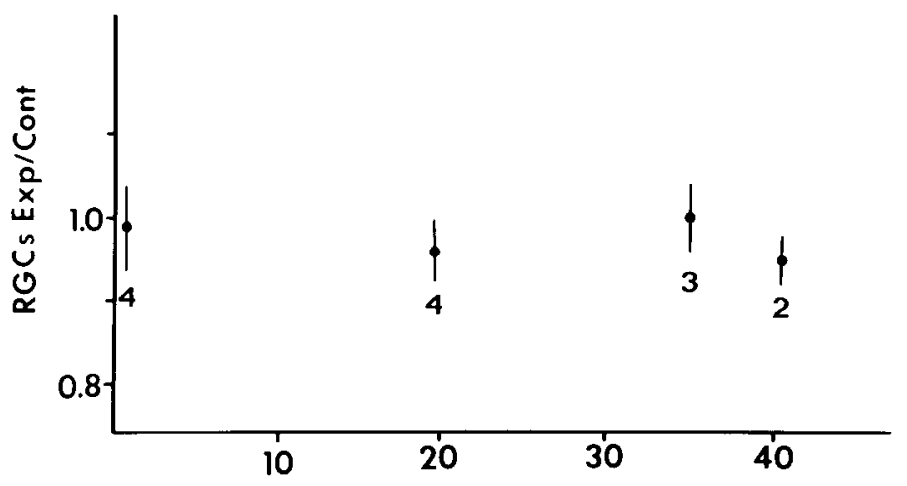

DAYS POST IMPLANT

Figure 9 . The ratio of cell number in the RGC layer of experimental eyes to that of control eyes is plotted against the number of days atter the IIXElvax pellet was implanted. No significant difference was found between those animals with nerve cuff implants versus those with intraocular implants; therefore, the data from both groups have been pooled for this figure. Error bars represent standard error at each time point.

In all of these experiments there remains the possibility that TTX is influencing some aspects of the system other than its activity. The fact that the optic fibers continue to transport both HRP and $\left[{ }^{3} \mathrm{H}\right]$ proline indicates that they have relatively normal axonal transport, and the HRP-filled terminal arbors that we traced from the flat mounts did not show any signs of degeneration. We have not found any significant differences in the number or somal area of cells in the RGC layer of Rana tadpoles following treatment with TTX for up to a month. This indicates that retinal development is proceeding normally despite the lack of $\mathrm{Na}^{+}$-dependent action potentials, consistent with the report of Harris (1980) that axolotl eyes transplanted to TTX-secreting Taricha newts develop and differentiate normally. However, a recent study of the effects of chronic TTX administration on regeneration (Edwards and Grafstein, 1983) indicates that TTX slows the overall rate of regeneration and reduces the fast axonal transport of nucleosides (Grafstein and Edwards, 1982) in the regrowing fibers. Thus, it could be argued that the TTX-induced prevention of rescgregation during host optic nerve regeneration in the three-eyed tadpoles after optic nerve crush was the result of a slowing of the regeneration process and, hence, a delay in the formation of eye-specific bands. Moreover, this same criticism applies to the studies in goldfish (Boss and Schmidt, 1982; Meyer, 1982), since the method used to produce segregation involves forcing regenerating fibers to the ipsilateral tectum. We do not believe that a slowing of the regeneration process is responsible for the prevention of segregation for two reasons. First, both in the studies of goldfish and in our experiments in the three-eyed tadpoles, the eye-specific segregation was blocked for a longer duration than would be expected, given the delay in regeneration reported for goldfish optic nerve during chronic TTX treatment (Edwards and Gratstein, 1983). Second, the fact that TTX poisoning of intact nerves causes the already banded projections to desegregate in three-eyed tadpoles provides stronger evidence for the specific role of activity in eye-specific segregation since the decline in nucleoside synthesis and transport that occurs in regenerating fibers treated with TTX apparently does not occur in intact fibers following chronic activity blockade (Grafstein and Edwards, 1982).

Thus, eye-specific segregation in the experimentally induced dually innervated tecta of Rana pipiens and goldfish appears to share a common mechanism with ocular dominance columns in the cat visual cortex, where intraocular TTX injections have also been shown to inhibit segregation (Stryker, 1981, 1983). Since the retinotectal projection of the frog and the fish are normally entirely crossed, these animals do not have any need for a special mechansm for eye-specific segregation; therefore, it is reasonable to assume that the segregation of two competing afferent projections in some way reflects the response of the normal mapping mechanisms to this unique situation. In fact, several theoretical models of map formation predict the source-specific segregation of afferents when the fibers are made to interact competitively (von der Malsburg and Willshaw, 1976; von der Malsburg, 1979; Constantine-Paton, 1982).

The essential element in these models is that two independent mechanisms operate in the normal animal to ensure appropriate map formation. The overall alignment and gross topography of the map are provided by differential adhesion between ganglion cell terminals and tectal cells from corresponding retinal and tectal regions. Such gross adhesion differences have been demonstrated (Gottlieb et al., 1976; Bonhoeffer and Huf, 1980). However, a second mechanism preserves the relative order among the fibers by some type of competitive interaction, which stabilizes adjacent terminals if they arise from neighboring ganglion cell bodies and destabilizes adjacent terminals if they arise from spatially distant cells in the retina. When two ganglion cell terminal populations attempt to innervate the same postsynaptic cells, the adhesive interactions spread both projections across the tectum, to connect with the appropriate tectal regions. If only this mechanism were in operation, the terminals from both eyes would form completely overlapping, continuous projections. However, if in addition, there is a mechanism that stabilizes terminals from neighboring ganglion cells when they synapse on the same tectal cell or group of cells, the fibers from the one eye will tend to terminate in the same region, whereas those from different eyes will tend to segregate. The result of both processes operating simultaneously is the formation of eye-specific bands.

In this context, we interpret the results of our experiments on TTX and segregation to indicate that the role of activity during normal map formation is to mediate the competition among terminals that stabilizes terminals from neighboring retinal cells. This interpretation is consistent with recent reports that TTX blocks the "fine-tuning" of 
the retinotectal map during optic nerve regeneration in goldfish (Meyer, 1983; Schmidt and Edwards, 1983), but not the overall alignment or gross topography of the projection (Harris, 1980; Meyer, 1983; Schmidt and Edwards, 1983). This conclusion is further supported by the present experiments. Occasionally the fibers from the third eye split to innervate both host tecta, but they only form bands in the retinotopically appropriate region, not through the full extent of the tectum (Law and Constantine-Paton, 1981). When animals with these split projections are treated with TTX to cause fiber desegregation, the fibers remain in the roughly appropriate tectal region. Therefore, we propose that the activity in the optic nerves normally acts to refine the topography of the retinotectal map by providing a basis for preservation of the neighborhood relations of ganglion cell bodies in their tectal terminal arbors. Furthermore, since elimination of patterned visual input by dark rearing three-eyed tadpoles fails to prevent band formation, (Law, 1982), it is likely that the spontaneous activity in the ganglion cell axons is sufficient for the fiber interactions.

At present, the details of the activity-dependent mechanism are unknown. In all of the models cited above, in order for the activity of the presynaptic cells to code for their retinal proximity, the action potentials of neighboring RGCs must be temporally correlated to a greater degree than that of non-neighboring cells. There is considerable evidence in several species that the spontaneous activity patterns of ganglion cells of the same center type are highly correlated when their receptive fields overlap; no correlation in spontaneous activity is observed between cells with nonoverlapping receptive fields (Rodieck, 1967; Arnett, 1978; Arnett and Spraker, 1981; Mastronarde, 1983a, b, c). Recent data in Rana tadpoles indicate that ganglion cells of similar type with overlapping receptive fields have temporally correlated patterns of spontaneous activity in this species as well (T. A. Reh, unpublished observation). Another essential element in our model, as well as in those of others that postulate the involvement of neural activity in eye-specific segregation and map formation (von der Malsburg and Willshaw, 1976; Whitelaw and Cowan, 1981), is that the synapses between RGC axons and tectal cells vary in their strength depending on the temporal correlation of the synaptic transmission. When two axons that have formed synapses on the same tectal cell fire coincidently, both synapses will be strengthened. Alternatively, if the two fibers have asynchronous patterns of activity, the connections they have with the same cell will be weakened. The strengthening of mutual connections as a result of coincident firing patterns in two fibers could operate by a mechanism such as that proposed by Hebb (1949) as a model for learning. Hebb (1949) proposed that connections might be strengthened if the pre- and postsynaptic cells were coincidently active. The temporal summation provided by the simultaneous activation of two (or more) presynaptic fibers with synapses on the same cell would thus increase the likelihood of postsynaptic activation for that cell and concomitantly would stabilize the active synapses. Although there has yet to be any direct demonstration that synapses can behave along the lines envisioned by Hcbb (1949) in the retinotectal system, the computer models of map formation and eye-specific segregation have successfully employed this idea (von der Malsburg and Willshaw, 1976; Willshaw and von der Malsburg, 1976; Whitelaw and Cowan, 1981)

The hypothesis that the pattern of electrical activity might specify the connections made during neural ontogenesis has been considered as a potential explanation for a wide variety of experimental results, obtained in several systems (see Stent, 1973; Changeux and Danchin, 1976; Harris, 1981, for review). However, although it appears likely that a certain amount of activity is noccssary for the normal maturation of many areas of the nervous system, e.g., the neuromuscular junction, it is not clear to what extent a particular pattern of activity is involved in determining which connections are sustained. Evidence demonstrating that binocularity of visual neurons is affected by modifications in the visual world in mammals (for review see Movshon and Van Sluyters, 1981) and by eye rotation in
Xenopus (Keating, 1981; Udin and Keating, 1981) supports the hypothesis that coincident activity causes the selective stabilization or maintenance of synapses from positions on the two retinas viewing corresponding points of the visual world. The possibility that the pattern of spontaneous activity provides some degree of specificity has been dramatically demonstrated by recent results in the kitten visual cortex (Stryker, 1983), in which ocular dominance column formation, blocked by intraocular injections of TTX, could be induced by asynchronous but not synchronous direct electrical activation of the optic nerves. Thus, in addition to providing some trophic support to the developing visual system (Kupperman and Kasamatsu, 1983), the pattern of spontaneous discharge may also contribute to the selective synaptogenesis and synapse elimination that occurs prior to, and after, eye opening in the cat (Archer et al., 1982; Kalil et al. 1983). In this context, the effects seen from modification of the visual world are superimposed upon a tonic discharge and may act via the same mechanism to use the pattern of activity to specify the connections between neurons.

\section{References}

Archer, S. M., M. W. Dubin, and L. A. Stark (1982) Abnormal development of kitten retino-geniculate connectivity in the absence of action potentials. Science 217: 743-745.

Arnett, D. W. (1978) Statistical dependence between neighboring retinal ganglion cells in goldfish. Exp. Brain Res. 32: 49-53.

Arnett, D., and T. E. Spraker (1981) Cross-correlation analysis of the maintained discharge of rabbit retinal ganglion cells. J. Physiol. (Lond.) 317: 29-47.

Bonhoeffer, F., and J. Huf (1980) Recognition of cell types by axonal growth cones in vitro. Nature 288: 162-164.

Boss, V., and J. T. Schmidt (1982) Tests for a role of activity in the formation of ocular dominance patches. Soc. Neurosci. Abstr. 8: 668.

Changeux, J. D., and A. Danchin (1976) Selective stabilization of developing synapses as a mechanism for the specification of neuronal networks. Nature 264: 705-712.

Constantine-Paton, M. (1982) The retinotectal hookup: The process of neural mapping. In Developmental Order: Its Origin and Regulation, S. Subtelny, ed., pp. 317-349, Alan R. Liss, Inc., New York.

Constantine-Paton, M., and M. I. Law (1978) Eye-specific termination bands in tecta of three-eyed frogs. Science 202: 639-641.

Constantine-Paton, M. E. Pitts, and T. A. Reh (1983) The relationship between retinal axon ingrowth, terminal morphology, and terminal patterning in the optic tectum of the frog. J. Comp. Neurol. 218: 297-313.

Currie, J., and W. M. Cowan (1974) Some observations on the early development of the optic tectum in the frog (Rana pipiens), with special reference to effects of early eye removal on mitotic activity in the laval tectum. J. Comp. Neurol. 156: 123-142.

Czeh, G., R. Gallego, N. Kudo, and M. Kuno (1978) Evidence for the maintenance of moloneurone properties by muscle activity. J. Physiol. (Lond.) 281: 239-252.

Edwards, D. L., and B. Grafstein (1983) Intraocular tetrodotoxin in goldfish hinders optic nerve regeneration. Brain Res. 269: 1-14.

Fawcett, J. W., and D. G. Willshaw (1982) Compound eyes project stripes on the optic tectum in Xenopus. Nature 296: 350-352.

Fraser, S. E., C. Ide, and R. L. Meyer (1982) Eye dominance columns formed by an isogenic double nasal frog. Soc. Neurosci. Abstr. 8: 450.

Gaze, R. M., M. J. Keating, A. Ostberg, and S. H. Chung (1979) The relationship between retinal and tectal growth in larval Xenopus. Implication for the development of the retinotectal projection. J. Embryol. Exp. Morphol. 53: 103-143.

Gottlieb, D. K., K. Rock, and L. Glaser (1976) A gradient of adhesive specificity in developing avian retina. Proc. Natl. Acad. Sci. U. S. A. 73: 410-414.

Grafstein, B., and D. L. Edwards (1982) Effect of physiological activity in goldfish optic axons on axonal transport of protein and nucleosides. In 
Axoplasmic Transport in Physiology and Pathology, D. G. Weiss and A. Gorio, eds., pp. 21-26, Springer-Verlag, Berlin.

Harris, W. A. (1980) The effects of eliminating impulse activity on the development of the retinotectal projection in salamander. J. Comp. Neurol. 194: 303-317

Harris, W. A. (1981) Neural activity and development. Annu. Rev. Physiol. 43: $689-710$

Hebb, D. O. (1949) Organization of Behavior, John Wiley \& Sons, Inc., New York

Kalil, R. E., M. W. Dubin, G. L. Scott, and L. A. Stark (1983) Effects of retinal ganglion cell blockade on the morphological development of retinogeniculate synapses. Soc. Neurosci. Abstr. 9: 25.

Keating, M. J. (1981) The organization of the developing visual system. In Development in the Nervous System, D. R. Garrod and J. D. Feldman, eds., pp. 35-60, Cambridge University Press, Cambridge, England.

Kuppermann, B. D., and T. Kasamatsu, T. (1983) Changes in geniculate cell size following brief monocular blockade of retinal activity in kittens. Nature 306: 465-468

Langer, R., and J. Folkman (1976) Polymers for the sustained release of proteins and other macromolecules. Nature (Lond.) 263: 797-800.

Law, M. (1982) The competitive effects of a second optic projection on the retinotectal system in the frog, Rana pipiens. Ph.D. thesis, Princeton University, Princeton, NJ.

Law, M. I., and M. Constantine-Paton (1980) Right and left eye bands in frogs with unilateral tectal ablations. Proc. Natl. Acad. Sci. U. S. A. 7: 2314-2318

I aw, M. I., and M. Constantine-Paton (1981) Anatomy and physiology of experimentally produced striped tecta. J. Neurosci. 1: 741-759.

LeVay, S., D. H. Hubel, and T. N. Wiesel (1975) The pattern of ocular dominance columns in macaque visual cortex revealed by a reduced silver stain. J. Comp. Neurol. 159: 559-576.

Levine, R., and M. Jacobson (1975) Discontinuous mapping of retina onto teclum intervated by both eyes. Brair Res. 98: 172-176.

Mastronarde, D. N. (1983a) Correlated firing of cat retinal ganglion cells. I. Spontaneously active inputs to $X$ - and $Y$-cells. J. Neurophysiol. 49: 303324.

Mastronarde, D. N. (1983b) Correlated firing of cat retinal ganglion cells. II. Responses of $X$ - and $Y$-cells to single quantal events. J. Neurophysiol. 49 : 325-349.

Mastronarde, D. N. (1983c) Interactions between ganglion cells in cat retina. J. Neurophysiol. 49: 350-365.

Meyer, R. (1979) Extra optic fibers exclude normal fibers from tectal regions in goldfish. J. Comp. Neurol. 183: 883-902.

Meyer, R. L. (1982) Tetrodotoxin blocks the formation of ocular dominance columns in goldfish. Science 218: 589-591.

Meyer, R. L. (1983) Tetrodotoxin inhibits the formation of refined retinotopography in goldfish. Dev. Brain Res. 6: 293-298.

Movshon, J. A., and R. C. Van Sluyters (1981) Visual neural development. Annu. Rev. Psychol. 32: 477-522.

Norden, J., and M. Constantine-Paton (1983) Evidence for postsynaptic regulation of synaptic density in three-eyed frogs. Soc. Neurosci Abstr. 9. 468.

Ostberg, A., and J. Norden (1979) Ultrastructural study of degeneration and regeneration in the amphibian tectum. Brain Res. 168: 441-455.

Reh, T. A., and M. Constantine-Paton (1983) Qualitative and quantitative measures of plasticity during the normal development of the Rana pipiens retinotectal projection. Dev. Brain Res. 10: 187-200.
Reh, T. A., and M. Constantine-Paton (1984) Retinal ganglion cell terminals change their projection sites during larval development of Rana pipiens. J. Neurosci. 4: 442-457.

Reh, T. A., E. Pitts, and M. Constantine-Paton (1983) The organization of the fibers in the optic nerve of normal and tectumless Rana pipiens. J. Comp. Neurol. 218: 282-296.

Rhine, W. D. D. S. T. Hsieh, and R. L. Langer (1980) Polymers for sustained macromolecular release: Procedures to fabricate reproducible delivery systems and control release kinetics. J. Pharm. Sci. 69: 265-270.

Rodieck, R. W. (1967) Maintained activity of cat retinal ganglion cells. J. Neurophysiol. 30: 1043-1071.

Schmidt, J. T., and D. L. Edwards (1983) Activity sharpens the map during the regeneration of the retinotectal projection in goldfish. Brain Res. 269 : 29-39.

Shumway, W. (1940) Stages in the normal development of Rana pipiens. I. External forms. Anat. Rec. 83: 309-315.

Silberstein, G. B., and C. W. Daniel (1982) Elvax 40P implants: Sustained, local release of bioactive molecules influencing mammary ductal development. Dev. Biol. 93: 272-278.

Sperry, R. W. (1963) Chemoaffinity in the orderly growth of nerve fiber patterns and connections. Proc. Natl. Acad. Sci. U. S. A. 50: 703-710.

Springer, A. D., and S. M. Cohen (1981) Optic fiber segregation in goldfish with two eyes innervating one tectal lobe. Brain Res. 225: 23-36.

Stent, G. S. (1973) A physiological mechanism for Hebb's postulate of learning. Proc. Natl. Acad. Sci. U. S. A. 70: 997-1001.

Straznicky, C., and D. Tay (1982) Retinotectal map formation in dually innervated tecta: A regeneration study in Xenopus with one compound eye following bilateral optic nerve section. J. Comp. Neurol. 206: 119130.

Straznicky, C., D. Tay, and J. Hiscock (1980) Segregation of optic fiber projections into the eye-specific bands in dually-innervated tecta in Xenopus. Neurosci. Lett. 19: 131-136.

Stryker, M. P. (1981) Late segregation of geniculate afferents to the cat's visual cotex after recovery from binocular impulse blockade. Soc. Neurosci. Abstr. 7: 842.

Stryker, M. P. (1983) Developmental strategies for selective synapse formation. Soc. Neurosci. Abstr. 9: 452.

Taylor, A. C. and J. J. Kollros (1946) Stages in the development of Rana pipiens larvae. Anat. Rec. 94: 7-23.

Udin, S. B., and M. J. Keating (1981) Plasticity in a central nervous pathway in Xenopus: Anatomical changes in the isthmotectal projection after laval eye rotation. J. Comp. Neurol. 203: 575-594.

von der Malsburg, C. (1979) Development of ocularity domains and growth behavior of axon terminals. Biol. Cybernet. 32: 42-69.

von der Malsburg, C., and D. J. Willshaw (1976) Mechanism for producing continuous neural mapping: Ocularity dominance stripes and ordered retinotectal projections. Exp. Brain Res. Suppl. 1: 463-469.

Whitelaw, V. A., and J. D. Cowan (1981) Specificity and plasticity of retinotectal connections: A computational model. J. Neurosci. 1: 13691387.

Willshaw, D. J., and C. von der Malsburg (1976) How patterned neural connections can be set up by selt-organization. Proc. R. Soc. Lond. (Biol.) 194: $431-445$

Willshaw, D. J., and C. von der Malsburg (1979) A marker induction mechanism for the establishment of ordered neural mapping: Its application to the retinotectal problems. Philos. Trans. R. Soc. Lond. (Biol.) 287: 203243. 